\title{
Opportunities and Barriers Perceived by Secondary School Agriculture Teachers in Implementing the GPS Cows Learning Module
}

\author{
Amy Cosby ${ }^{\mathrm{a}}$, Mark Trotter ${ }^{\mathrm{a}}$, Jaime Manning ${ }^{\mathrm{a}}$, Bobby Harreveld ${ }^{\mathrm{b}}$ and Jessica Roberts ${ }^{\mathrm{c}}$ \\ Corresponding author: Amy Cosby (a.cosby@cqu.edu.au) \\ anstitute for Future Farming Systems, School of Health, Medical and Applied Sciences, CQUniversity, Rockhampton \\ QLD, 4701 \\ ${ }^{\mathrm{b} S}$ School of Education and Arts, CQUniversity, Rockhampton QLD, 4701 \\ ${ }^{\mathrm{c}}$ Marcus Oldham Centre for the Study of Agribusiness, Marcus Oldham College, Waurn Ponds, Geelong, Victoria, \\ 3216
}

Keywords: agri-tech education, GPS livestock tracking, secondary school, professional learning

International Journal of Innovation in Science and Mathematics Education, 27(4), 67-75, 2019

Special Issue: Agricultural Education

\begin{abstract}
Within the agriculture sector the use of digital technologies is rapidly expanding. There is a growing shortage of skilled people considering a career within this sector to support the uptake of agricultural technology. The GPS Cows program is designed to improve secondary school student's knowledge and skills of emerging agricultural technologies. It highlights a range of opportunities and potential career options available to students in agriculture. This collaborative project combines the expertise and passion of researchers, industry professionals and educators in both Australia and the USA. A pilot workshop was run with ten teachers from nine Queensland and New South Wales secondary schools. Teachers participated in lectures and practical workshops, developed data analysis skills and took part in a World Café style focus group. The focus group findings highlighted that for the GPS Cows program to be implemented in secondary school classrooms, excellent resources from the GPS Cows team are needed, combined with ongoing support and guidance. Nevertheless, the participating teachers felt that their students would both engage and enjoy participating in the GPS Cows program and realise the opportunities the agricultural sector offers.
\end{abstract}

\section{Introduction}

The United Nations predicts that the global population will reach 9.7 billion by the year 2050 (United Nations, 2015). To feed this growing population, particularly in developing economies, it has been reported that food production will need to double in a manner which is both socially and environmentally sustainable (Godfray et al., 2010). Australia is well placed to contribute to this increased demand for food with $65 \%$ of agriculture produce valued at $\$ 44.7$ billion exported across the world (Department of Foreign Affairs, n.d.). Asia is the largest market for Australian agricultural exports with $66 \%$ of goods sent to this region. Importantly, approximately $75 \%$ of these goods from Australia are imported by emerging or developing Asian economies (ABARES, 2018). To remain competitive on a global level, agricultural businesses must be innovative and continue to adopt new technologies (Australian Government Parliamentary Committee 2016). To 
enable this, the agricultural workforce must have sufficient digital literacy skills and be confident in implementing agricultural technologies across the value chain. Furthermore, with an estimated four jobs available for every tertiary agricultural graduate in Australia, there is a skills shortage in the industry that needs addressing (Pratley \& Acuna, 2015).

The GPS Cows program (gpscows.com) is one initiative that is focused on building the skills and knowledge of high school students studying agriculture. The program aims to ensure that when the next generation enter the workforce they have the potential to utilise agricultural technologies (agri-tech) to increase the profitability, productivity and sustainability of Australian farms. GPS Cows is a collaborative project bringing together researchers, industry professionals and educators in both Australia and the USA who understand the importance of, and are passionate about, engaging students in agri-tech. The ultimate aim of GPS Cows is to increase the capacity of high school students in emerging agri-tech, specifically tools and systems which provide animal location, behaviour and state data (LBS), and to encourage them to consider tertiary study and career options in the agricultural sector.

Tracking livestock using Global Positioning Systems (GPS) has been a focus of animal behaviour research for over 20 years (Bailey et al., 2018). Animal location data can be used to interpret and manage grazing behaviour (Turner, Udal, Larson, \& Shearer, 2000), pasture utilisation (Putfarken, Dengler, Lehmann, \& Hardtle, 2008), grazing distribution (Ganskopp, 2001; Roberts et al., 2015), reproductive activity (Fogarty et al., 2015) and potentially detect predation events (Manning et al., 2014). This technology is anticipated to become economically viable and commercially available in the near future (Bailey, Trotter, Knight, \& Thomas, 2018). The potential benefits of commercial tracking technologies and LBS information has been reported for the beef cattle industry to be between $\$ 280$ and $\$ 808$ million over the next ten years (Trotter et al., 2018). The number of benefits and applications were also realised and highlighted by surveyed participants in Trotter et al., (2018). Examples include using LBS data to monitor animal welfare, detect disease and injury, increase mustering efficiency and identify shy feeders (Trotter et al, 2018). To increase farm productivity, profitability and environmental sustainability, producers and agricultural professionals will need the skills and knowledge required to collect and interpret real-time LBS data. Understanding this data will improve a producer's capacity to manage livestock through manipulating animal behaviour or selecting animals predisposed to more efficiently utilise the landscape. However, a large proportion of farmers and agricultural professionals (including school teachers) lack the required expertise to implement some of these new and emerging agri-tech solutions. Therefore, by increasing the capacity, knowledge and skills of the next generation of these professionals we hope to be able to contribute to the upcoming needs of industry.

There are numerous resources available online to support food and fibre education (Primary Industries Education Foundation Australia, 2016), however the mere existence of these materials is not enough to successfully engage and motivate teachers to utilise them (Bray \& Cay, 2017). This is primarily due to a lack of time to find and trial resources and fit them into teaching schedules. Furthermore, many of these learning resources are focussed on theoretical activities and the availability of materials that relate to emerging technologies is extremely limited. Thus, identifying available resources that utilise authentic and relatable data which link to emerging technology and accessible professional learning is a challenge. 
Classroom teachers are often the drivers of change and champions of innovative ideas in schools. To make use of externally developed resources, teachers require the time and support to develop confidence to implement these in the classroom. Therefore, professional learning opportunities are vital to the success and uptake of developed resources (Tytler, 2007). This is likely to be even more critical when endeavouring to integrate more complex digital technologies which themselves are only starting to emerge in the industry.

These factors were important considerations for the development and delivery of the GPS Cows learning resources by high school teachers. To be able to provide students with the skills and knowledge needed to collect and analyse LBS information, and ultimately accelerate adoption of this technology throughout the agricultural supply chain, the support for teachers must be substantial and well designed. Understanding this mandate, the project team brought together agricultural teachers from nine secondary schools to trial and further develop the preliminary learning resources developed by the first and second authors of this paper and seek their perceptions on how the implementation of GPS Cows in the classroom could be supported.

\section{Methodology}

Ten teachers from nine secondary schools (three in New South Wales and six in Queensland) participated in the pilot GPS Cows workshop at CQUniversity's Rockhampton campus in May 2017. The schools that were represented at the workshop from Queensland are Dalby State High School, Beenleigh State High School, Rockhampton State High School, Rockhampton Girls Grammar, Malanda State High School and Atherton State High School. Kempsey High School, Tumut High School and Murrumburrah High School were the New South Wales representatives. A strategic decision was made by the research team to select schools which had a strong agriculture program and passionate teacher based on previous interactions to participate in the workshop. Teachers from these schools were approached by phone and invited to participate. All travel costs were covered by the project with schools only required to cover teacher relief time.

The workshop consisted of a series of lectures on GPS livestock tracking, seeing the technology in action and practical sessions, allowing teachers to develop skills in data analysis. The last session of the workshop involved all 10 teachers partaking in a World Café (Schieffer et al., 2004) style focus group, reflecting on what they had learnt during the workshop (Human Ethics Approval no. H17/04-068). After their participation in the workshop each school was given five GPS tracking collars, which they deployed on their school livestock. This enabled these teachers to apply their learnings from the workshop and trial the learning resources developed with their students in their own environment. Although there were no formal opportunities for workshop participants to catch up during the project once the workshop was complete, the research team has been in close contact with teachers to provide assistance where required to implement the GPS Cows program.

\section{World Café method}

The World Café method has been described as 'a practical way to enhance the human capacity for collaborative thought' (Schieffer, Isaacs, \& Gyllenpalm, 2004, p. 2). The World Café model comprises of five basic components which can be modified to suit the needs of the activity. These are: 
1. Setting the scene through the creation of an environment for the activity to take place.

2. An introduction to how the World Café method works and the context for the activity.

3. Creation of small groups of people around the table who discuss the question.

4. Posing the question to the group providing a focus for the discussion.

5. The sharing of individual insights as a result of the discussion for each question (The World Café, 2018).

This method facilitates constructive discussion of critical questions whilst building and fostering collaborative relationships between participants, whilst allowing for effective data collection (Fouche' \& Light, 2011). The World Café technique was chosen to elicit responses from teachers about the GPS Cows program because it is known to allow cross-pollination of ideas and allows for participants to share their thoughts and opinions in an open, welcoming and social environment (Fouche' \& Light, 2011). These factors were important considerations for the current research to make the teachers feel comfortable sharing information with the researchers to allow them to develop the GPS Cows program.

\section{GPS Cows focus group using the World Café method}

A large room at the CQUniversity Rockhampton campus was set up with round tables with markers, post-it ${ }^{\mathrm{TM}}$ notes and butchers paper made available to participants. The purpose of the focus group was to identify the motivations, barriers and required support to implementing the GPS Cows program and this was made clear at the start to the participants. The four questions posed in the focus group were:

1. Why do you want to participate in the GPS Cows program?

2. What are the biggest barriers to your participation?

3. What can the GPS Cows program do to support you?

4. What do you perceive are the benefits to student's participation in GPS Cows program?

Seated in small groups of two to three people at round tables, each participant was given the opportunity to discuss their opinions on the question for ten minutes. After this, each person was given three post-it notes and four minutes to write down their top three answers for each question. At the conclusion of the four minutes the whole group came back together and each participant read out their three answers to the question to everyone. These answers were then placed onto a large piece of butchers' paper and were arranged into themes. At the conclusion of the group discussion participants separated into groups of two to three. Each group then spent fifteen minutes discussing the individual responses to each question and assessing whether they were placed under the correct theme or if a new theme needed to be created. The answers written on the post-it ${ }^{\mathrm{TM}}$ notes and the themes were recorded in $\mathrm{Excel}^{\circledR}$ to preserve the data.

\section{Results and discussion}

There were four key themes identified for each of the four questions, with the number of responses received under that theme identified in Tables 1-4. As each individual had three post it ${ }^{\mathrm{TM}}$ notes for each question they were able to contribute more than one answer to each theme, with the number one reason why they wanted to take part in the GPS cows program being industry relevance (Table $1)$. 
Table 1: Why do you want to participate in GPS Cows? (n=10)

\begin{tabular}{|l|l|}
\hline Theme & Number of responses \\
\hline Industry relevance & 9 \\
\hline Engage STEM/new tech in ag context & 8 \\
\hline Increase school profile/student retention & 7 \\
\hline Personal enjoyment/interest & 6 \\
\hline
\end{tabular}

Interestingly, a major reason the teachers wanted to be involved was their own personal interests and that they believed they would derive enjoyment from their participation. Responses from participants of the focus group included, "I really like this stuff - ag tech innovation...' and it's "fun for all involved." This is an important factor that cannot be emphasised enough to facilitate the uptake of GPS Cows. If teachers are enthusiastic about the program, and the knowledge and skills they can personally develop, they are more likely to be able to effectively implement the learning module in their classroom (Kunter et al., 2008). This enthusiasm is imperative for our teachers to be the drivers of change, champions of innovative ideas and to inspire secondary school students to consider a career in Agriculture. However, it is important to note that the teachers who participated in the pilot GPS Cows workshop were selected to attend because of their high-quality agricultural programs in their schools. Further investigation is required to determine if the majority of agriculture teachers are of the same opinion and are interested in pursuing programs like GPS Cows.

One of the issues faced in the preliminary development of the GPS Cows learning resources was the availability of a reliable and economically sustainable platform to analyse the data collected. At the time of the workshop, the project team members were still unsure as to what software could be utilised by schools to analyse LBS data. From the participant answers received, the relevance of the GPS Cows project to the agricultural industry appeared to be a real drawcard to participate in the program. To analyse the LBS data in a way that is relevant to industry a Geographic Information System (GIS) that schools could easily (and cheaply) access is required. Researchers often use costly GIS software to interpret livestock location and behaviour data (Bailey, 2009). The price of this software is often prohibitive to secondary schools. Fortunately, ESRI ${ }^{\circledR}$ (a major GIS software company) developed ArcGIS Online ${ }^{\circledR}$ (a condensed version of ArcGIS Pro ${ }^{\circledR}$, a software that is frequently used by researchers) which is free to secondary schools participating in the GPS Cows program. This accessibility has enabled students to develop skills relevant to industry. Using the ArcGIS ${ }^{\circledR}$ platform has the added benefit that students will not only be able to analyse the data they collect, but also share and compare data across Australia and the USA. It is hoped that in the next stage of the project that teachers from Australia and the USA will interact allowing project participants to learn about agricultural production systems across the world.

The biggest barrier identified by teachers in implementing the GPS Cows learning resources was their personal technical ability and skills (Table 2). Teachers highlighted concerns about their "knowledge of data manipulation and use of computers' and 'understanding/teaching [of] statistical analysis techniques." Another significant barrier is time, as teachers, especially those with a school farm to manage, are often very time poor. Access to computers for their class to use 
was another concern. Internet access or speed was not explicitly mentioned as a barrier by teachers, however as the ArcGIS Online platform requires the internet, this might be an additional issue faced in utilising GPS Cows. This is a significant issue when such emphasis is being placed on improving the ICT skills and digital literacy of students across a large component of the curriculum ( $\mathrm{Ng}$ 2012).

Table 2: What are the biggest barriers to implementing GPS Cows in your school? $(\mathbf{n}=10)$

\begin{tabular}{|l|l|}
\hline Theme & Number of responses \\
\hline Learning the technical skills required & 9 \\
\hline Time & 7 \\
\hline Access to computers for classes & 3 \\
\hline Space to incorporate into current teaching program & 3 \\
\hline
\end{tabular}

In relation to implementation of the GPS Cows program in schools, the key theme identified by participants relates to the necessity of continued support and guidance after the conclusion of the workshop (Table 3). It was important to participants that they could contact members of the GPS Cows team so that they could "...assist in problem solving e.g. data analysis" and disseminate findings from other school projects. The development of resources was another key area of support required, in conjunction with follow up workshops which are being considered as part of the dissemination of GPS Cows.

Table 3: What can the GPS Cows team do to help implement GPS Cows? $(n=10)$

\begin{tabular}{|l|l|}
\hline Theme & Number of responses \\
\hline Provide support and guidance & 13 \\
\hline Development of resources & 10 \\
\hline Follow up workshops & 5 \\
\hline
\end{tabular}

It was clear from the statements made by the teachers that it was important that the GPS Cows resources were of high quality to support delivery in the classroom. Comments such as "assist with scaffold papers/data to allow students to practice stat[istics] skills before using project data" and "workbook instructables on how to do tasks such as importing data into cloud applications" highlighted the need for clear instructions which students could easily follow. With this in mind, learning resources have subsequently been designed by the research team, consisting of a series of lessons which can be used individually or as a sequence totalling 25 hours of content. It became evident in trialling the initial resources with teachers that, as suggested by Hmelo-Silver et al., (2007), extensive scaffolding was required to guide and support student learning. Consequently, the outcomes of this study include that future iterations of the GPS Cows program will provide clear scaffolding to assist student learning. The resources will consist of preparatory information introducing students to the basic concepts of GPS and why livestock location and behaviour data is important to the agricultural industry. Furthermore, details of how farmers can use this information to increase the productivity, profitability and environmental sustainability of their enterprise will be included. To acknowledge the different learning styles of students, resources 
will be developed using different forms including written instructions, videos and hands-on activities (Pashler, McDaniel, Rohrer, \& Bjork, 2008).

The key reason teachers believed students would benefit from participating in the GPS Cows program was that they would be more engaged with the content because they would be given the "opportunity to participate 'at the cutting edge' of technology,' and 'access to meaningful, relevant and current research" (Table 4).

Table 4: What do you think will be the benefits to students participating in GPS Cows? $(\mathbf{n}=\mathbf{1 0})$

\begin{tabular}{|l|l|}
\hline Theme & Number of responses \\
\hline Increased engagement & 11 \\
\hline Enjoyment & 9 \\
\hline Develop skills in technology application & 7 \\
\hline Discover opportunities & 3 \\
\hline
\end{tabular}

Participants perceived students would enjoy the content that comprises the GPS Cows learning module as it would be "exciting, new, different to anything we have done before." Teachers believed their students would develop skills in technology application, leading to "better highlevel application of academic skills into agriculture" and to the "possibilit[y] to advance their own farm in the future and show parents the possibilities." A key outcome for the project is to showcase possible careers to students in the agricultural industry, and hence it was encouraging to see the theme of student's discovering opportunities emerge with responses such as GPS Cows could 'broaden their ag pathways on the horizon' and allow them to develop a "skill set relevant to industry/future careers in STEM" (i.e. Science, Technology, Engineering, and Mathematics). Since the pilot workshop, the addition of a lesson on career options has been included to reinforce the wide variety of people that the agricultural sector requires, including engineers, programmers, software developers, nutritionists, animal behaviourists and scientists to name a few.

A video case study has been developed by the researchers showcasing how a farmer is conducting research on their farm using GPS tracking collars and how they intend to use the data to make decisions on the farm. This will demonstrate to students how digital literacy skills are applied in the real world, highlighting one of the many applications of GPS tracking technology and encouraging students to contemplate their own applications and research questions. Furthermore, by introducing students to a real farmer, it was believed that student expectations of what a typical farmer looked like may be changed to include someone that undertakes numerous jobs and is aware of how technology can make production, sustainability, profitability and animal welfare improvements.

\section{Conclusion}

The GPS Cows program now consists of a series of learning resources available free of charge on gpscows.com. It has the potential to contribute to the development of skills and knowledge of next generation's agricultural workforce. The focus group highlighted that teachers are keen to participate for a range of reasons including to make their teaching program more industry relevant and to demonstrate agriculture's strong links to STEM. Interestingly, teachers are also wanting to 
participate to develop their own knowledge and satisfy personal interests in learning about agritech. However, there are key barriers teachers face in implementing the GPS Cows program in their schools. A lack of technical knowledge and skills, and finding the time in their already busy teaching programs were noted as the biggest challenges to overcome. Teachers will be provided with support and high-quality resources will be developed as these were identified as key areas where the GPS Cows team could assist in the implementation of the program in schools. Importantly, teachers perceived their students would both engage and enjoy participating in the GPS Cows program, as well as opening their eyes to the opportunities the agricultural sector offers.

The knowledge gained from this focus group has been utilised to further develop the GPS Cows program and the associated resources. Future research will focus on evaluating the effectiveness of the resources developed with teachers who attend a series of workshops to be delivered across New South Wales in 2018-19 as part of the implementation of the new Stage 4 Technology Mandatory curriculum (Logan \& Cavanagh, 2018). An assessment of the GPS Cows program will be conducted following the Kirkpatrick Four Levels of Training Evaluation model (Kirkpatrick \& Kirkpatrick, 2006). At the conclusion of the workshop participants will complete a survey to evaluate the 'reaction' and 'learning' components of the framework. A follow-up survey in Term 4, 2019 will be conducted to assess the 'behaviour' and 'results' components (Kirkpatrick \& Kirkpatrick, 2006).

\section{Acknowledgments}

The GPS Cows program is funded by Queensland Agricultural Training Colleges, Queensland Department of Agriculture and Fisheries and the New South Wales Department of Education.

\section{References}

ABARES. (2018). Australian agricultural overview. Retrieved from http://data.daff.gov.au/data/warehouse/agcomd9abcc004/agcomd9abcc20180918_xV5mH/AgCommodities2018 09_AgOverview_v1.0.0.pdf

Australian Government Parliamentary Committee. (2016). Smart farming inquiry into agricultural innovation. House of Representatives Standing Committee on Agriculture and Industry. Retrieved from http://www.aph.gov.au/Parliamentary_Business/Committees/House/Agriculture_and_Industry/Agricultural_inno vation/Report

Bailey, D. W., Trotter, M. G., Knight, C. W., \& Thomas, M. G. (2018). Use of GPS tracking collars and accelerometers for rangeland livestock production research. Translational Animal Science, 2(1), 81-88.

Bailey, D. W. 2009. Enhancement of sustainable livestock grazing through selection and training. Final report for SW09-054. https://projects.sare.org/project-reports/sw09-054/

Bray, H., \& Cay, B. (2017). Room to grow: Challenges for the future of food and fibre education in Australia. Retrieved from http://www.piefa.edu.au/uploads/9/8/9/8/98986708/room_to_grow_portrait2.0.pdf

Department of Foreign Affairs. (n.d.) Agricultural trade. Australian Government. Retrieved from https://ffat.gov.au/trade/organisations/wto/Pages/agricultural-trade.aspx

Fogarty, E. S., Manning, J. K., Trotter, M. G., Schneider, D. A., Thomson, P. C., Bush, R. D., \& Cronin, G. M. (2015). GNSS technology and its application for improved reproductive management in extensive sheep systems. Animal Production Science, 55(10), 1272-1280.

Fouché, C., \& Light, G. (2011). An invitation to dialogue: 'The World Café' in social work research. Qualitative Social Work, 10(1), 28-48.

Ganskopp, D. (2001). Manipulating cattle distribution with salt and water in large arid-land pastures: a GPS/GIS assessment. Applied Animal Behaviour Science, 73(4), 251-262.

Godfray, H. C. J., Beddington, J. R., Crute, I. R., Haddad, L., Lawrence, D., Muir, J. F., ... \& Toulmin, C. (2010). Food security: The challenge of feeding 9 billion people. Science, 327(5967), 1185383. 
Hmelo-Silver, C. E., Duncan, R. G., \& Chinn, C. A. (2007). Scaffolding and achievement in problem-based and inquiry learning: A response to Kirschner, Sweller, and Clark (2006). Educational psychologist, 42(2), 99-107.

Kirkpatrick, D.L., \& Kirkpatrick, J.D. (2006). Evaluating training programs. San Francisco, CA: Berrett-Koehler Publishers Inc.

Kunter, M., Tsai, Y. M., Klusmann, U., Brunner, M., Krauss, S., \& Baumert, J. (2008). Students' and mathematics teachers' perceptions of teacher enthusiasm and instruction. Learning and Instruction, 18(5), 468-482.

Logan, T., \& Cavanagh, M. (2018, November 22). Agriculture to be a mandatory unit in New South Wales high schools. Retrieved from https://www.abc.net.au/news/rural/2018-11-22/agriculture-to-be-mandatory-unit-innsw-schools/10518776

Manning, J.K., Fogarty E. S., Trotter, M. G., Schneider, D. A., Thomson, P. C., Bush, R.D., \& Cronin G. M. (2014). A pilot study into the use of global navigation satellite system technology to quantify the behavioural responses of sheep during simulated dog predation events. Animal Production Science, 54(10), 1676-1681.

$\mathrm{Ng}$, W. (2012). Why digital literacy is important for science teaching and learning. Curriculum and Leadership Journal, 10(10). Retrieved from http://www.curriculum.edu.au/leader/why_digital_literacy_is_important_for_science_teac,34913.html?issueID= 12610

Pashler, H., McDaniel, M., Rohrer, D., \& Bjork, R. (2008). Learning styles: Concepts and evidence. Psychological Science in the Public Interest, 9(3), 105-119.

Putfarken, D., Dengler, J., Lehmann, S., Hardtle, W. (2008). Site use of grazing cattle and sheep in a large-scale pasture landscape: A GPS/GIS assessment. Applied Animal Behaviour Science, 111(1-2), 54-67.

Pratley, J.E., \& Botwright Acuna, T. (2015). From adversity comes strength-repositioning education in agriculture. 17th Australian Society of Agronomy Conference, 1-9.

Primary Industries Education Foundation Australia. (2016). PrimeZone: The place for all your primary industry resources. Retrieved from http://www.primezone.edu.au

Roberts, J., Trotter, M., Schneider, D., Lamb, D., Hinch, G., \& Dobos, R. (2015). Daily grazing time of free-ranging cattle as an indicator of available feed. 7th European Conference on Precision Livestock Farming, Milan, Italy, 491-500.

Schieffer, A., Isaacs, D., \& Gyllenpalm, B. (2004). The World Café: Part one. World, 18(8), 1-9.

The World Café. (2018). The World Café Method. Retrieved from http://www.theworldcafe.com/key-conceptsresources/world-cafe-method/

Trotter, M., Cosby, A., Manning, J., Thomson, M., Trotter, T., Graz, P., Fogarty, E., Lobb, A., \& Smart, A. (2018). Demonstrating the value of animal location and behaviour data in the red meat value chain. Meat and Livestock Australia Limited. Retrieved from https://www.mla.com.au/research-and-development/search-rd-reports/finalreport-details/Demonstrating-the-value-of-animal-location-and-behaviour-data-in-the-red-meat-value-chain/3754

Turner, L. W., Udal, M. C., Larson, B.T., \& Shearer, S.A. (2000). Monitoring cattle behavior and pasture use with GPS and GIS. Canadian Journal of Animal Science, 80(3), 405-413.

Tytler R. (2007). Re-imagining science education engaging students in science for Australia's future. Australian Education Review. Retrieved from https://research.acer.edu.au/aer/3/

United Nations. (2015). World Population Prospects The 2015 Revision: Key findings and advance tables. Department of Economic and Social Affairs. Retrieved from

https://esa.un.org/unpd/wpp/Publications/Files/Key_Findings_WPP_2015.pdf 